\title{
A Clinical Study Measuring Dental Aerosols with and without a HVE Device
}

\author{
Adam Nulty ${ }^{1}$, Chris Lefkaditis ${ }^{2}$, Patrik Zachrisson ${ }^{3}$, Quintus Van Tonder ${ }^{4}$ and Riaz Yar ${ }^{5}$ \\ 1 University of Leeds, Woodhouse Lane. Leeds. LS2 9JT. England dnabn@leeds.ac.uk
}

Received: date; Accepted: date; Published: date

\begin{abstract}
:
(1) Introduction: External high volume extraction devices may offer a way to reduce any aerosol particulate generated. The aim of this study was to measure the particle count during dental aerosol procedures and compare the results to when a High Volume Extraction device is used; (2) Methods: A comparative clinical study measuring the amount of PM1, PM2.5 and PM10 aerosol particulate with and without the use of an external High Volume Extraction device was undertaken. In total, 10 restorative procedures were monitored with an an industrial Trotec PC220 particle counter. The air sampler was placed at the average working distance of the clinicians involved in the study $420 \mathrm{~mm}$.; (3) Results: In the present study aerosol particulate was recorded at statistically significantly increased levels during dental procedures without an external high volume extraction device versus with the device. The null hypothesis was rejected, in that significant differences were found between the results of the amount of aerosol particle count with and without a High Volume Extraction device.; (4) Conclusion: If the results of the present study are repeated in an in vivo setting, an external high volume suction device may potentially lower the risk of transmission of viral particulate.
\end{abstract}

Keywords: Covid-19; HVE; Aerosol; Dentistry; Particle; Suction; External; PM1; PM2.5; PM10; Drilling;

\section{Introduction}

Aerosols and the Sars-Cov-2 virus

In light of the Sars-Cov-2 pandemic, the United States Occupational Safety and Health administration have classified aerosols produced in dentistry as one of the very high risk occupations for transmission of the disease[1]. Before investigating the present study, we must discuss how aerosols are generated and what sized particles are present within any potential aerosol that is generated in a dental procedure to understand the significance of reducing the aerosols generated. An aerosol is a dispersion system consisting of solid and liquid particles of various sizes which are suspended in a gas medium.[2] Whilst using this definition, and the three important elements of aerosols, we must consider that it is normal for an aerosol to be suspended in the air only if it's less than 10 microns in size[2, 3]. This is because as these droplets decrease in size, so does their relative mass. As such the impact of gravity on these particles reduces and they can be suspended in the air for much longer.[4]

The size of the particles that can be potentially suspended in the aerosols produced can range from 0.001-100 microns[5]. These particles can be defined according to their size: coarse particles are 2.5-10 microns (PM10 classification), fine particles are under 2.5 microns (PM2.5), and ultra-fine 
particles are under 0.1 microns (PM1). For human transmission of disease, the infectious dose required is small. Viral and bacterial agents have an affinity for specific components of cells and tissues along with pathogenic factors[6]. The oral-nasal breathing pathway can channel air particles over 10 microns in size. This poses risk as particles under 10 microns in size can therefore enter the respiratory system and smaller particles under 2.5 microns can enter the alveoli sac. Ultra-fine particles, such as the Sars-Cov-2 virus molecule, which are sub 1 micron can potentially enter the circulatory system through this mechanism directly or being carried on a larger particle[7,8] The mechanism of breathing in living creatures can also create aerosols in the form of bio-aerosols[9]. These droplets can be produced in large numbers, for example upto three thousand in just a single cough. High projectile particles can also be generated in larger numbers (over forty thousand) in the action of sneezing[10].

How do airborne infections spread

Even before specific infectious agents such as bacteria and viruses were discovered the potential of infection by the airborne route was recognized, for example the bubonic plague, also known as the 'black plague', which was recorded as spread via an airborne route.

This is seen as a concern in more recent times in air travel. In one report the mycobacterium bacillus causing tuberculosis was spread through passengers on an aeroplane[11]. Passengers seated closer to the source of the infection were more likely to contract the disease.

The exact mechanisms by which sars-cov-2 virus is spread remain under investigation but current understanding points to transmission through aerosol droplets.[12,13,14] Many worldwide governments and healthcare authorities have therefore advised dental practitioners to proceed with only emergency and essential procedures and avoid elective dental procedures altogether.[15,16]

\section{Dental Aerosols}

The mechanical action of tools used in the dental clinic can produce suspended particles as aersols, such as the use of fast and slow dental handpieces, ultrasonic scalers and air water syringes.[17]. These tools use high powered air or fast turning mechanical micromotors to work, which can create these aerosols through the kinetic energy acting in the process of dental instrumentation[18,19].

As the mouth contains saliva, blood and other substances, micro-organisms and viral particles are ever present[2]. Studies have shown that the bacterial load around the mouth of the patient during an oral treatment procedure is higher as compared to when they are not operated on in a dental procedure[9]. Dental unit water lines are another potential source in contributing to the microorganisms carried in the aerosol generation. These water lines that supply the handpieces and syringes can become contaminated through use, as water backfires or from the incoming water used in the dental chair unit.[20] The water spray is usually the most visible portion of the aerosol to the naked eye, and is noticed by the patient and dental staff.[21]

One recent study looked at how ultrasonic scaling can transmit particulate aerosol for upto six feet and without an air current this particulate can remain suspended from 35 minutes to several hours[22]. If the suspended particulate is over 10 microns, gravity can cause these particles to settle on the surrounding surfaces such as the patient and the immediate clinical area for upto two meters[3,23]. During these dental procedures, various dental equipment such as dental handpieces, air-water syringes, ultrasonic scalers, and air polishing units are known to produce colony forming units compared to pre- and post-operative via these bio-aerosols generated. $[24,25,26]$

\section{Can splatter from dental procedures spread disease?}

Miller et al have concluded that bio-aerosols can contain millions of bacteria per cubic foot of air.[27] King et al have stated that aerosols retrieved from six inches away from a patient, the colony forming units were substantially reduced through aerosol reduction systems.[28]

During a conventional dental procedure, the patient is required to sit with their mouth open, exposing the naturally occurring fluids such as saliva and blood.[29] During a dental procedure that 
uses ultrasonic scalers, the air/water syringe or high-speed air turbine or micromotor devices, the mechanical action can spread these bodily fluids through splatter out of the operating site into the surrounding environment. It is this splatter that can take the form of a spray of variously sized droplets.[30] The constituents of these droplets and their relative size have been given the dental terms 'splatter' and 'aerosols'.[31] Larger particles that are not suspended can be visible where spread occurs outside of the operating field but particles and droplets under 50 microns are not visible to the naked eye. These smaller particles have a minute mass (under 10 microns) and can remain in the air for minutes or even hours[32] until they are inhaled by humans. Once inhaled they can travel to the fine lung alveoili potentially causing respiratory infections.[33]

These aerosols and nuclei can also enter the ventilation systems of the dental clinic and spread to other operating sites.[34]

Thus the potential spread of the sars-cov-2 virus in a dental clinic is characterised via three pathways; direct contact of infected oral fluids, direct contact with contaminated surfaces and inhalation of infectious particulate aerosols. [35]

The aim of this study was to measure the particle count during dental aerosol procedures and compare the results to when a High Volume Extraction device is used.

The null hypothesis was that no differences would be found in the amount of aerosol particle count with or without a High Volume Extraction device.

\section{Materials and Methods}

\section{Air sampler device}

In total, 5 different restorative procedures were monitored with an an industrial Trotec PC220 particle counter. This sampler is sent with a calibration certificate where the sampler is calibrated with a PC200/220 Filter for Zero Calibration by the manufacturer. The air sampler therefore does not need calibrating prior to use by the user. This air sampler conforms with ISO 215014 - which specifically refers to the Light Scattering Aerosol Particle Counters - and is accurate to within $+/-95 \%$ with a $5 \%$ particle coincidence loss. The sampler was used to measure the PM1 (particulate sized 1 micrometer $(\mu \mathrm{m})$ or less), PM2.5 (particulate sized 1-2.5 micrometer $(\mu \mathrm{m})$ ) and PM10 sized particulate (particulate sized 2.5-10 micrometer $(\mu \mathrm{m})$ ) generated in each procedure. The 5 different procedures were carried both without a HVE device in place and repeated separately with the HVE device in place to compare the effect of the HVE on the particle counts recorded. The air sampler uses multiangle laser scattering detection. Scattered light will be collected in a specified angle and according to the scattering intensity, equivalent particle diameters and the number of suspended particulate matter with different sizes in per unit volume can be obtained.

\section{Working Distance}

For each procedure the air sampler was placed at the average recorded working distance of the clinicians involved in the study $-420 \mathrm{~mm}$. Ie the working distance from each of the dentists was measured and then this average was used to place the air sampler on a unit the same distance from the model, and therefore the source, of the aerosol. Specifically and spacially, the sampler was placed at $420 \mathrm{~mm}$ directly to the right of the phantom head unit on an adjacent dental unit. For the purposes of the present study, no measurements were taken at distances closer or further from the source of the aerosol. The air sampler was taped around the seals and joints to prevent contamination of the unit and provide a wipeable surface between measurements.

\section{High Volume Extraction}

The unit used in this study was a Vacstation by Eighteeth. The VacStation uses a multi-level filtration system (HEPA, High-fiber cotton filter, Activated carbon, KMnO4, Ceramsite filter, 2nd HEPA 13), and UV C light. The Vacstation was placed with the circular suction orifice placed at $300 \mathrm{~mm}$ in front of the phantom head. This position would - in an in vivo setting - be positioned above 
the patient's chest and in front of their mouth. The Vacstation was turned on maximum suction setting. The Vacstation is capable of varying the suction setting but for the purposes of the present study, the setting was left on maximum for a repeatable effect.

\section{Study setting}

Volunteers for the study were four dentists working at a single dental clinic using the same chair unit. To avoid external factors affecting the results, the room pressure of the room was maintained at the same level with windows closed, no air conditioning and no air purifier running.

The sampling was performed on a phantom head model on a dental chair in the position of a patient. Ventilation of the room was turned off and windows closed. All units had the normal equipment functionality running (e.g. water cooling, standard saliva ejector) as used on the chair for normal practice.

On the day of the study, the volunteer dentists were instructed to perform normal restorative treatments on the model as described below.

The sampling period for the component of the study without the use of a high volume extractor was recorded from the start of that specific procedure. The procedure duration was of continuous use for 1 minute. The sampling measurement then continued for one minute or until the air particulate levels returned to normal levels.

\section{Procedures tested}

i) Intense (full blast) three-in-one air/water syringe (mixed air and water); The three in one air/water syringe was directed towards the lower anterior region with normal aspirator suction collecting the water produced.

ii) Micromotor high speed handpiece with water; The micromotor high speed handpiece was used to drill a lower anterior tooth on the dental model as mesial cavities. On the second procedure with the HVE device in place, the same tooth was drilled on the distal surface.

iii) Air turbine high speed handpiece with water; The air turbine high speed handpiece was used to drill a lower anterior tooth on the dental model as mesial cavities. On the second procedure with the HVE device in place, the same tooth was drilled on the distal surface.

iv) Slow speed handpiece with water; The slow speed handpiece was used to drill a lower anterior tooth on the dental model as mesial cavities. On the second procedure with the HVE device in place, the same tooth was drilled on the distal surface.

v) Ultrasonic scaling with water; The ultrasonic scaler was used to scale around the gingival margins of the lower anterior teeth on the model.

\section{Validation and background level}

The air sampler was used to measure the same room for one hour before and after procedures ended to analyse that there was no natural fluctuation of air particulate. Range:

- PM1 3-6 $\mu \mathrm{g} / \mathrm{m} 3$,

- PM2.5 6-8 $\mu \mathrm{g} / \mathrm{m} 3$,

- PM10 7-10 $\mu \mathrm{g} / \mathrm{m} 3$ sized particulate.

\section{Ethics Approval}

The sampling was performed using daily routines and complied with current sars-cov-2 protective measures but did not involve intervention on human subjects. No personal data of the participants was recorded and therefore there was no requirement for ethical approval.

\section{Statistical Analysis}

The data captured by the particle counter was tabulated in Excel spreadsheet for Mac 2016 and analysed in SPSS 26 by IBM. Comparisons were made using a one-way analysis of variance (ANOVA) for independent groups, with a Tukey significance level of 0.05 , of multiple comparisons using SPSS 
26 by IBM (a comparison of means for each procedure with and without the external high volume extraction device) was used to determine significance of each of the means. Significance level was set at $\mathrm{P}<0.05$ for all analyses.

\section{Results}

Results are shown for the measurement period of each particle count, PM1, PM2.5 and PM10. In Figures 1 and 2, the data is shown as a graph of particle count measured for each size of particulate during the procedure for one minute and for one minute after the procedure.

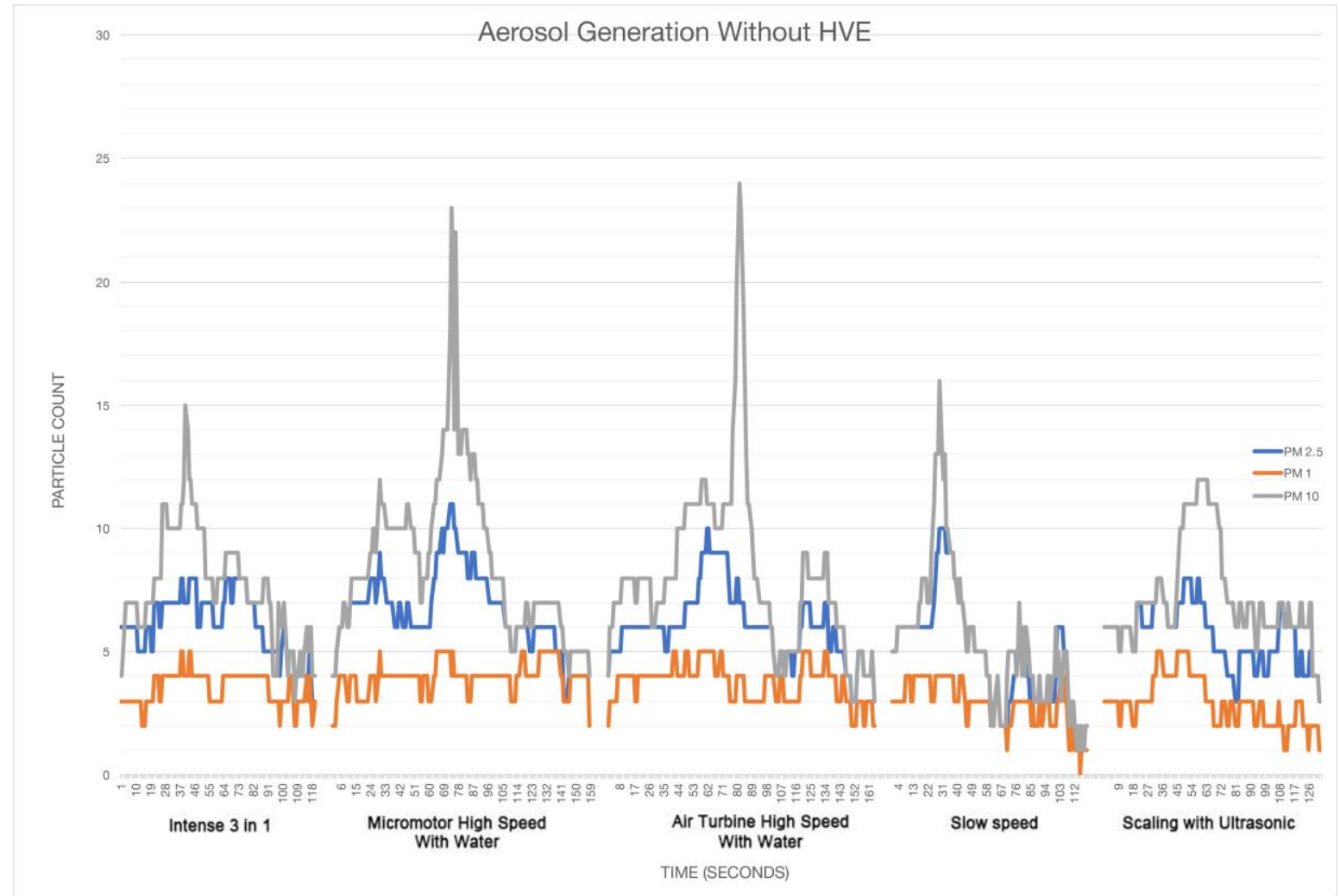




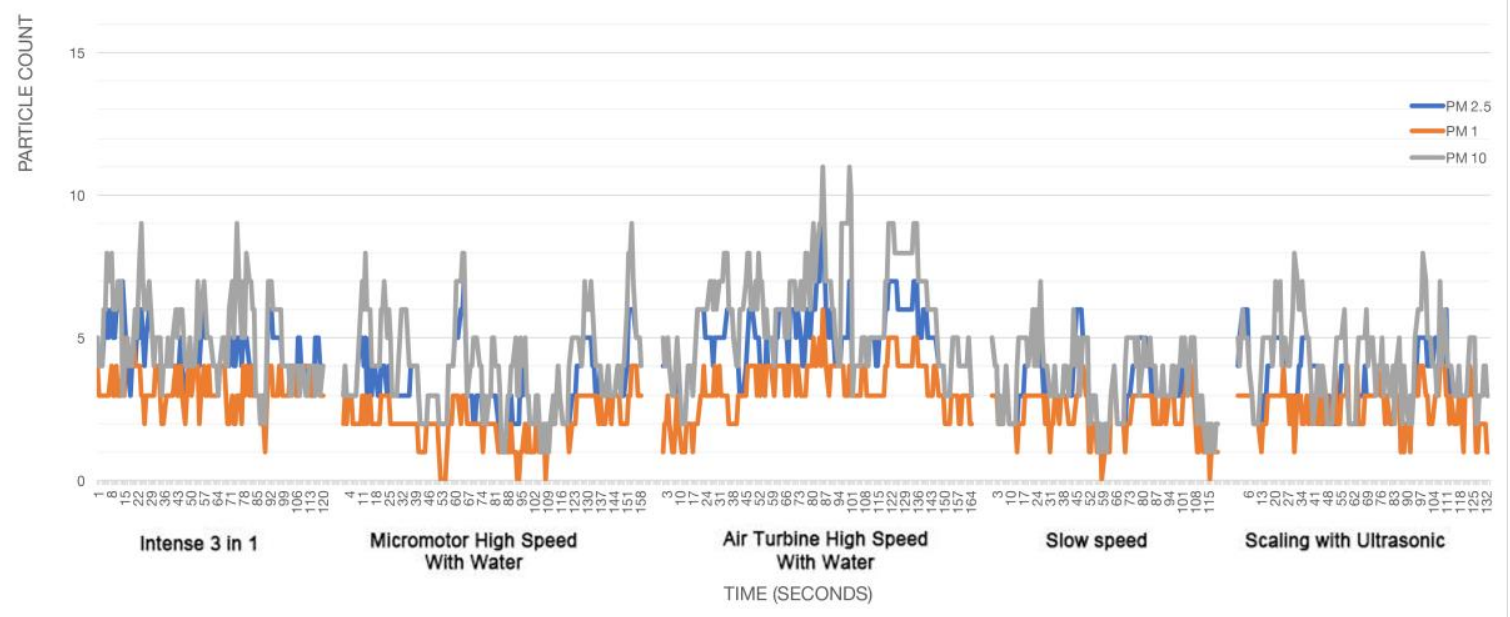

Figure 1. Aerosol generation without high volume suction used

Figure 2; Aerosol generation with high volume suction used

In the present study, there is a clear difference between the results as displayed on the two graphs displaying the data recorded over time.

Tables 1, 2 and 3 show the maximum particle count recorded during each procedure;

\begin{tabular}{|l|l|l|l|l|l|}
\hline PM1 & $\begin{array}{l}\text { Intense } \\
\text { Jin1 } \\
\text { Maximum } \\
\mu \mathrm{g} / \mathrm{m3}\end{array}$ & $\begin{array}{l}\text { Micromotor } \\
\text { Maximum } \\
\mu \mathrm{g} / \mathrm{m3}\end{array}$ & $\begin{array}{l}\text { Air Turbine } \\
\text { Maximum } \\
\mu \mathrm{g} / \mathrm{m3}\end{array}$ & $\begin{array}{l}\text { Slow } \\
\text { Speed } \\
\text { Maximum } \\
\mu \mathrm{g} / \mathrm{m3}\end{array}$ & $\begin{array}{l}\text { Ultrasonic } \\
\text { Maximum } \\
\mu \mathrm{g} / \mathrm{m3}\end{array}$ \\
\hline Without HVE & 5 & 5 & 6 & 4 & 5 \\
\hline With HVE & 4 & 4 & 6 & 4 & 4 \\
\hline Background & $3-6$ & $3-6$ & $3-6$ & $3-6$ & $3-6$ \\
\hline $\begin{array}{l}\text { \% Relative } \\
\text { Reduction } \\
\text { above } \\
\text { background }\end{array}$ & $\begin{array}{l}\text { Results } \\
\text { within } \\
\text { background } \\
\text { levels }\end{array}$ & $\begin{array}{l}\text { Results } \\
\text { within } \\
\text { background } \\
\text { levels }\end{array}$ & $\begin{array}{l}\text { Results } \\
\text { within } \\
\text { background } \\
\text { levels }\end{array}$ & $\begin{array}{l}\text { Results } \\
\text { within } \\
\text { background } \\
\text { levels }\end{array}$ & $\begin{array}{l}\text { Results } \\
\text { within } \\
\text { background } \\
\text { levels }\end{array}$ \\
\hline
\end{tabular}

Table 1; Maximum Particulate Counts Measured for PM1 particle size during each procedure $(\mu \mathrm{g} / \mathrm{m} 3)$ 


\begin{tabular}{|l|l|l|l|l|l|}
\hline PM2.5 & $\begin{array}{l}\text { Intense } \\
\text { 3in1 } \\
\text { Maximum } \\
\mu \mathrm{g} / \mathrm{m3}\end{array}$ & $\begin{array}{l}\text { Micromotor } \\
\text { Maximum } \\
\mu \mathrm{g} / \mathrm{m3}\end{array}$ & $\begin{array}{l}\text { Air Turbine } \\
\text { Maximum } \\
\mu \mathrm{g} / \mathrm{m} 3\end{array}$ & $\begin{array}{l}\text { Slow } \\
\text { Speed } \\
\text { Maximum } \\
\mu \mathrm{g} / \mathrm{m3}\end{array}$ & $\begin{array}{l}\text { Ultrasonic } \\
\text { Maximum } \\
\mu \mathrm{g} / \mathrm{m3}\end{array}$ \\
\hline Without HVE & 8 & 11 & 10 & 10 & 8 \\
\hline With HVE & 6 & 6 & 9 & 5 & 6 \\
\hline Background & $6-8$ & $6-8$ & $6-8$ & $6-8$ & $6-8$ \\
\hline $\begin{array}{l}\text { \% Reduction } \\
\text { above } \\
\text { background }\end{array}$ & $\begin{array}{l}\text { Results } \\
\text { within } \\
\text { background } \\
\text { levels }\end{array}$ & 100 & 100 & 100 & $\begin{array}{l}\text { Results within } \\
\text { background } \\
\text { levels }\end{array}$ \\
\hline
\end{tabular}

Table 2; Maximum Particulate Counts Measured for PM2.5 particle size during each procedure $(\mu \mathrm{g} / \mathrm{m} 3)$

\begin{tabular}{|l|l|l|l|l|l|}
\hline PM10 & $\begin{array}{l}\text { Intense } \\
\text { 3in1 } \\
\text { Maximum } \\
\mu \mathrm{g} / \mathrm{m3}\end{array}$ & $\begin{array}{l}\text { Micromotor } \\
\text { Maximum } \\
\mu \mathrm{g} / \mathrm{m3}\end{array}$ & $\begin{array}{l}\text { Air Turbine } \\
\text { Maximum } \\
\mu \mathrm{g} / \mathrm{m3}\end{array}$ & $\begin{array}{l}\text { Slow } \\
\text { Speed } \\
\text { Maximum } \\
\mu \mathrm{g} / \mathrm{m3}\end{array}$ & $\begin{array}{l}\text { Ultrasonic } \\
\text { Maximum } \\
\mu \mathrm{g} / \mathrm{m3}\end{array}$ \\
\hline Without HVE & 15 & 23 & 24 & 16 & 12 \\
\hline With HVE & 9 & 9 & 11 & 7 & 8 \\
\hline Background & $7-10$ & $7-10$ & $7-10$ & $7-10$ & $7-10$ \\
\hline $\begin{array}{l}\text { \% Reduction } \\
\text { above } \\
\text { background }\end{array}$ & 100 & 100 & 93 & 100 & 100 \\
\hline
\end{tabular}

Table 3; Maximum Particulate Counts Measured for PM10 particle size during each procedure $(\mu \mathrm{g} / \mathrm{m} 3)$; 


\begin{tabular}{|l|l|l|l|l|l|l|}
\hline & $\begin{array}{ll}\text { PM1 } \\
\text { Turkey } \\
\text { Non- } \\
\text { HVE to } \\
\text { HVE } \\
\text { Sig }\end{array}$ & $\begin{array}{l}\text { PM1 } \\
\text { HVE } \\
\text { Statisticall } \\
\text { y } \\
\text { Significant }\end{array}$ & $\begin{array}{l}\text { PM2.5 } \\
\text { Turkey } \\
\text { Non-HVE } \\
\text { to HVE } \\
\text {.Sig }\end{array}$ & $\begin{array}{l}\text { PM2.5 } \\
\text { HVE } \\
\text { Statisticall } \\
\text { y } \\
\text { Significant }\end{array}$ & $\begin{array}{l}\text { PM10 } \\
\text { Turkey } \\
\text { Non-HVE } \\
\text { to HVE } \\
\text {.Sig }\end{array}$ & $\begin{array}{l}\text { PM10 } \\
\text { HVE } \\
\text { Statisticall } \\
\text { y } \\
\text { Significant }\end{array}$ \\
\hline Intense 3in1 & 0.373 & No & 0.000 & Yes & 0.000 & Yes \\
\hline Micromotor & 0.000 & Yes & 0.000 & Yes & 0.000 & Yes \\
\hline Air Turbine & 0.000 & Yes & 0.000 & Yes & 0.000 & Yes \\
\hline Slow Speed & 0.000 & Yes & 0.000 & Yes & 0.000 & Yes \\
\hline Ultrasonic & 0.045 & Yes & 0.000 & Yes & 0.000 & Yes \\
\hline
\end{tabular}

Table 4 Statistical results of a Tukey comparison of means for each procedure.

We can see from statistical analysis in SPSS 26 that with a Tukey comparison of means (Table 4) there is a statistically significant difference in the data samples recorded for every dental procedure when an external high volume extraction device is used. The only exception to this is the PM1 particle count in a 3in1 procedure.

We can further examine this difference with a means plot for each particulate size - as shown in Figures 3, 4 and 5; 


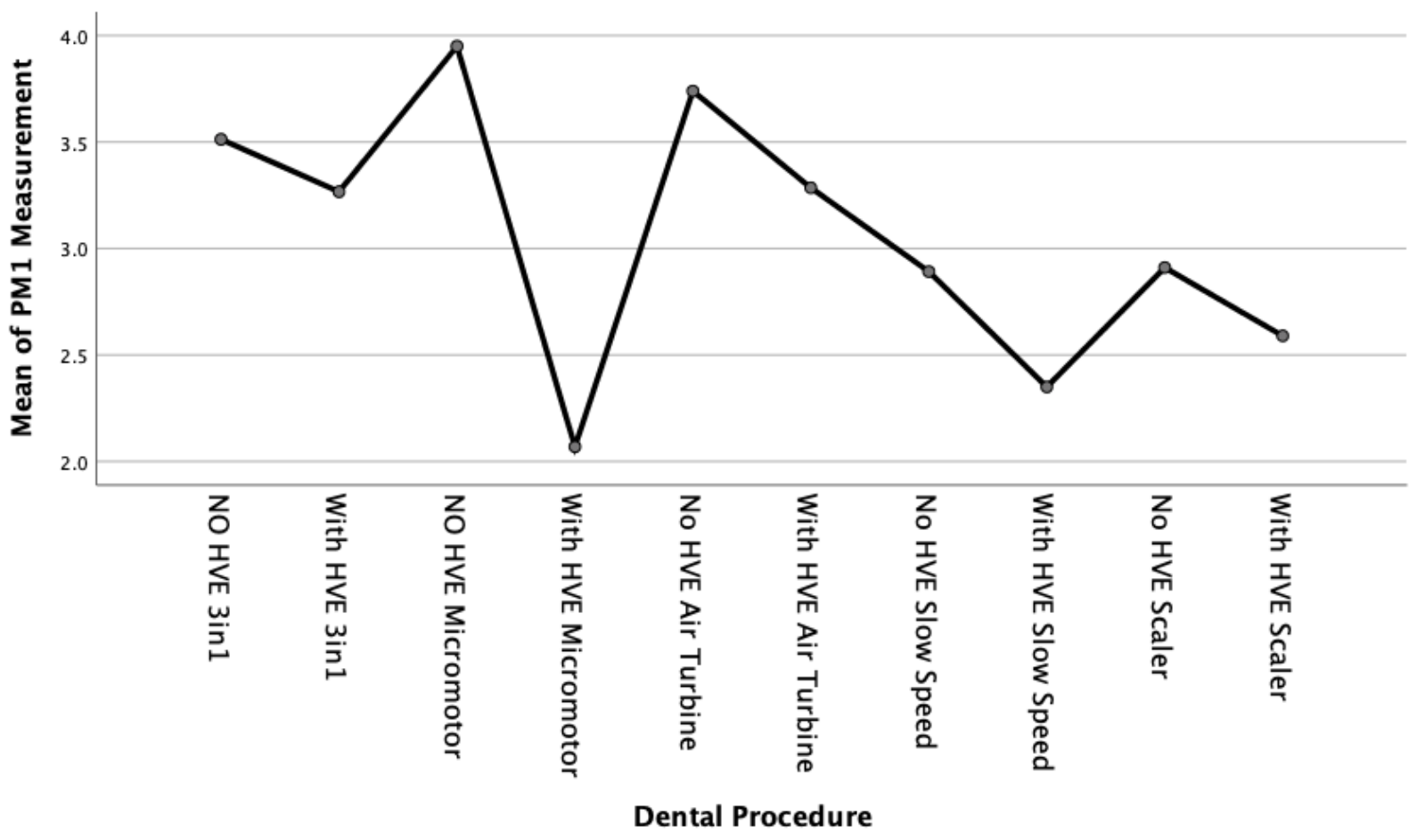

Figure 3; Means plot of PM1 particle count for each dental procedure

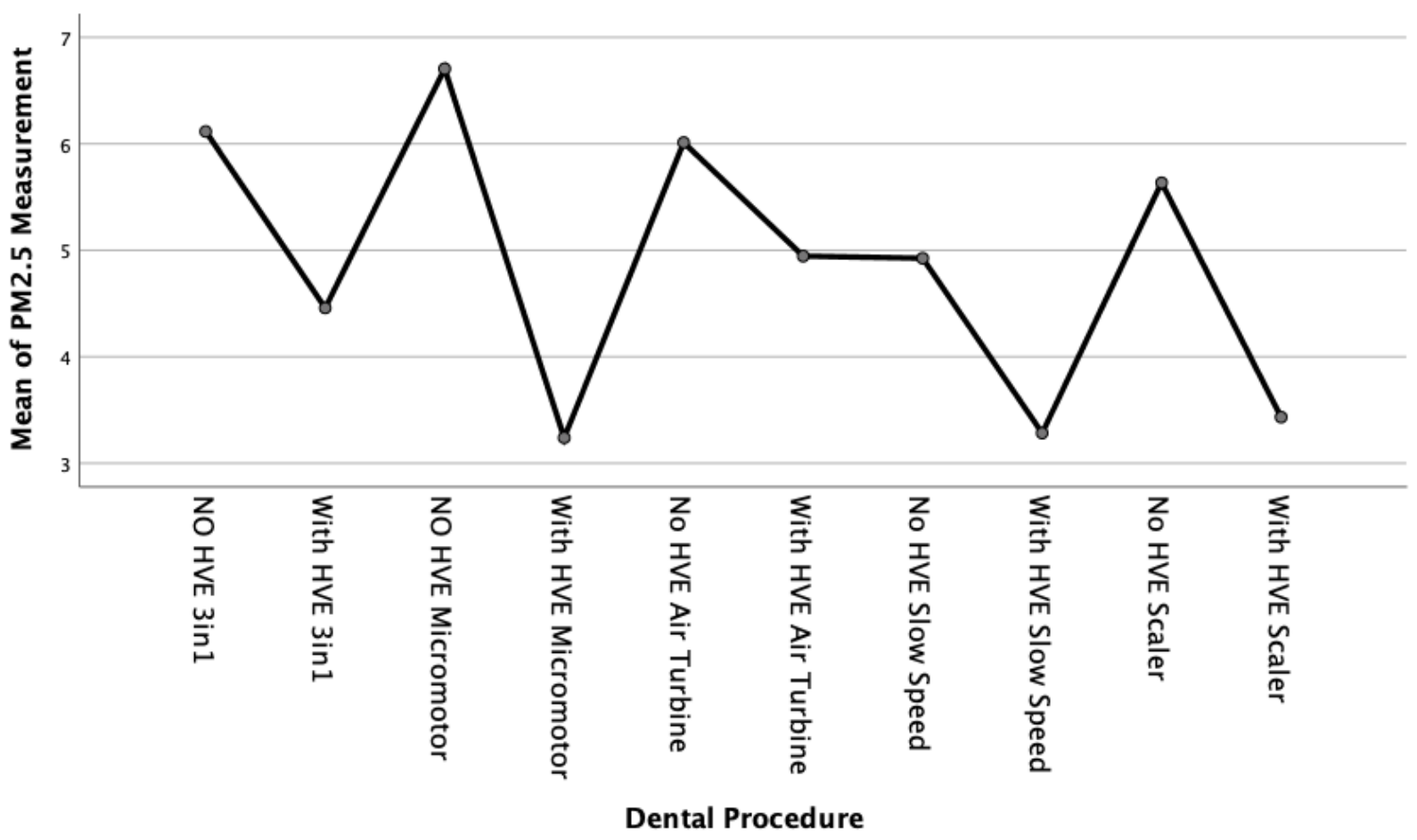

Figure 4; Means plot of PM2.5 particle count for each dental procedure 


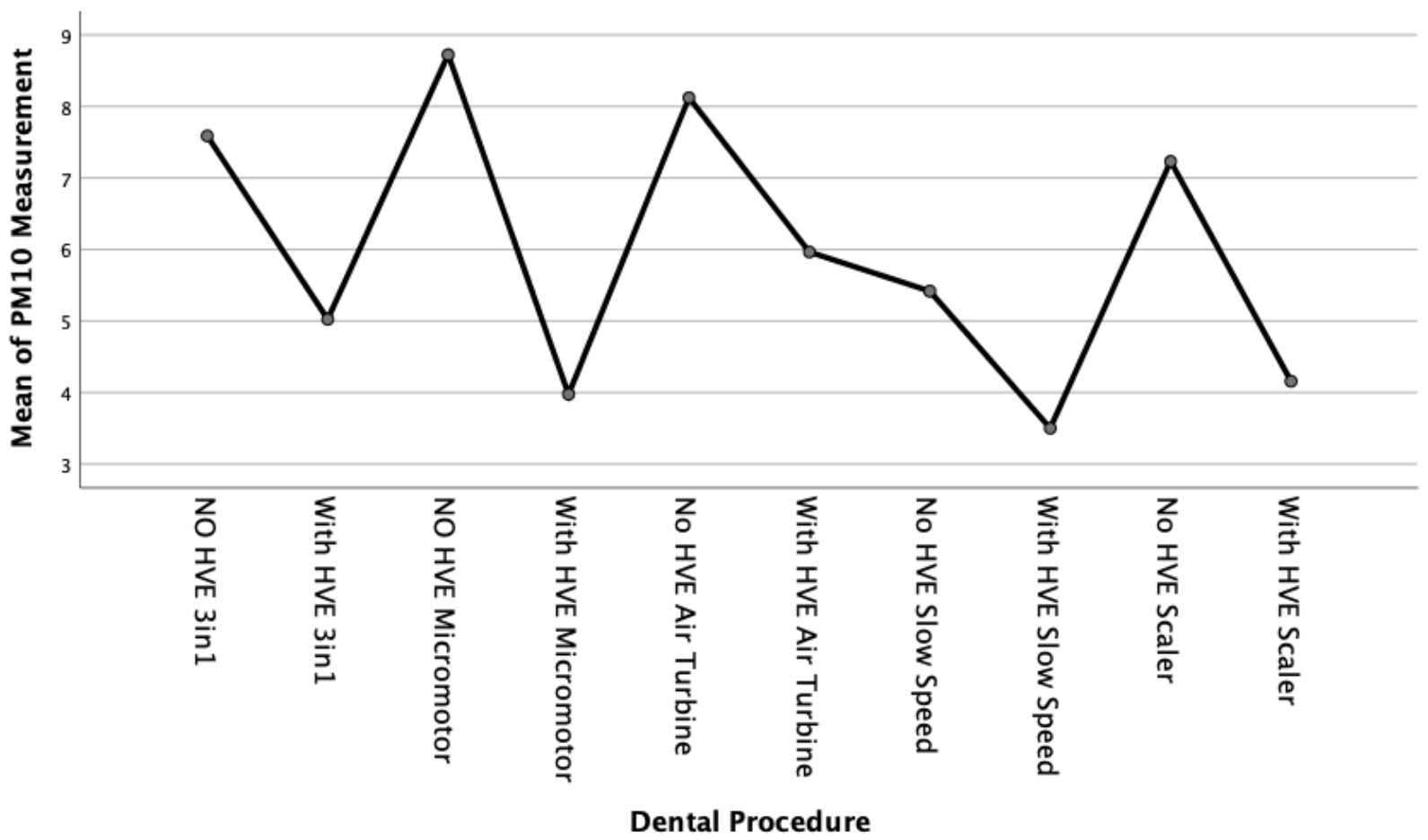

Figure 5; Means plot of PM10 particle count for each dental procedure

\section{Discussion}

The null hypothesis was rejected, in that significant differences were found between the results of the amount of aerosol particle count with and without a High Volume Extraction device. The purpose of the present study was to measure the particle count during dental aerosol procedures and compare the results to when a High Volume Extraction device is used. The reason why this is of particular importance in current dental practice is the risk of transmission of the SARS-CoV-2 virus through aerosol particulate.

\section{SARS-CoV-2 Viral Diameter and relevance to particulate sizing.}

Zhu et al have discussed "Electron micrographs of negative-stained 2019-nCoV particles were generally spherical with some pleomorphism. Diameter varied from about 60 to $140 \mathrm{~nm}$." Using this diameter and assuming the virus is a sphere[36] we can therefore assume that as the virus is approximately a thousandth of the aerosol particulate in this study, any PM1, PM2.5 or PM10 sized aerosol particulate produced may carry the virus and therefore potentially transmit the disease if inhaled.

Aerosol Sizes

PM1 sized particulate generated;

In the present study, the PM1 sized particulate generated with all procedures appears to remain within the range sampled within the control measurements with no procedure taking place. However, outside of the 3in1 procedure, there was a statistically significant reduction in particle count when an external high volume extraction device was used. 
There was a clear increase in PM2.5 particulate generated during the dental procedures. This statistically significant increase was approximately double the normal background sample measurements. With the use of an external high volume extraction HVE device, the samples taken during the five dental procedures were statistically significantly reduced. There was a slight increase in the measured levels towards the end of the air turbine procedure but this was statistically insignificant $(11 \mu \mathrm{g} / \mathrm{m} 3$ with HVE versus $24 \mu \mathrm{g} / \mathrm{m} 3$ without HVE).

PM10 sized particulate generated;

The PM10 sized particulate generated in each of the procedures followed a similar, yet amplified, pattern to the PM2.5 sized particulate generated. The maximum levels of particulate generated were approximately three fold the background levels of PM10. With the use of an external high volume extraction HVE device, the samples taken during the five dental procedures were statistically significantly reduced.

\section{Interpretation}

We can therefore interpret these results as meaning none, or very little PM1 particulate is generated during 3in1 dental procedures as the difference was statistically insignificant.

There is a statistically significant increase of between two and three times the background $\mu \mathrm{g} / \mathrm{m} 3$ levels of PM2.5 and PM10 sized particulate compared to the results recorded during dental procedures without an external HVE used.

\section{Biological Relevance}

One limitation in the interpretation of these results is the biological relevance with regards to the SARS-CoV-2 virus. This virus is new and relative infectivity and mechanisms of transmission are currently under investigation.

In the SARS outbreak in 2003, Kan et al. studied the relationship between particulate levels with mortality. The study showed that PM with aerodynamic diameter $10 \mathrm{~m}$ (PM10) were positively associated with the SARS mortality.[37]

It has also been reported that aerosols associated with highly virulent pathogens like SARS could travel more than two metres.[38] Whilst not of dental origin, Feng et al carried out an ecologic analysis that found a positive relationship between PM2.5 particulate count and viral transmission in Beijing [39].

Small aerosols have more potential to be inhaled deeply into the lung, which can potentially cause infection in the alveolar tissues of the lower respiratory tract.[40] Recent research work has been focusing on providing a better understanding on aerosol and droplet transmission, which has provided evidence that aerosols may play a major role in transmitting the SARS-CoV-2 virus.[41,42] Duguid et al. studied the number of droplets and aerosols generated sizes 1-100 $\mu \mathrm{m}$ and found that coughing and sneezing produced from a few to a few hundred droplets and aerosols per cubic metre.[43] However, controversy remains among many researchers as to the modes of transmission via droplet or aerosol and the quantifiable risk associated with levels of either.

In the present study aerosol particulate was recorded at statistically significantly increased levels during dental procedures without an external high volume extraction device versus with the device. These increased levels were around two dozen $\mu \mathrm{m}$ per cubic metre.

\section{Minimizing aerosols and splatter}

Recent studies have shown that the SARS-CoV-2 virus can be transmitted via particulate matter [44]. Historically, previous studies have shown that there is a positive correlation between PM2.5 and larger particulate sizes, and transmission of virus such as influenza.[45] The Centres for Disease Control and Prevention (CDC) carried out a study which showed that the Sars-CoV-2 virus was able to remain viable for upto 72 hours on some surfaces(32).

One could argue that the risk of transmission in the dental setting via aerosols is minor as the aerosol droplets may be entirely from the waterline. However when we look at a study on splatter and aerosol generated from an ultrasonic scaler without any coolant water used in vitro, there was still a substantial number of aerosol and 
splatter formed from small amounts of liquid placed at the operating site to simulate blood and saliva. [46] We therefore have to look at ways to mitigate this risk during the current sars-cov-2 crisis.

Harrel et al wrote that "no single approach or device can minimize the risk of infection to dental personnel and other patients completely. A single step will reduce the risk of infection by a certain amount, another step added to the first step will reduce the remaining risk, until such time as the risk is minimal."[30] This is a sensible approach to provide layered protection for risk mitigation.[47] Harrel also discusses that in the reduction of dental aerosols, the first layer of defense is personal protection barriers such as masks, gloves, visors, safety goggles and hair nets.[48] The second layer of defense is the routine use of an antiseptic preprocedural rinse with a mouthwash such as peroxyl/povidone iodine or chlorhexadine.[49] The third layer of defense is the regular use of a high volume evacuator (HVE) either by an assistant or attached to the instrument being used.[50] An additional layer of defense could also be the employment of a tool to scale back aerosol contamination that escapes the operating area, such as a HEPA filter.[51] These extra layers of defence are either commonly found or easily implemented in most dental practices.

It has also been recommended that dental practices install negative pressure airflow to prevent airborne transmission through aerosols.[52] Some, including Harrel et al, have suggested that using a $0.2 \%$ Chlorhexidine or Listerine mouthrinse pre-operatively could be of benefit as they have been shown to reduce the oral bacterial load in aerosols[23], but there are no high quality peer reviewed studies on the virucidal activity of Hydrogen Peroxide. Iodine has been hypothesided to be of greater value for this purpose than chlorhexidine [52]

The correctly placed high volume vacuum suction and evacuator near the handpiece and the mouth can reduce $90 \%$ of the output of aerosol.[24,53] During conservative practices, use of the rubber dam barrier is also thought to reduce the risk significantly upto $98.5 \%$ [54] The results for the present study confirm these figures whilst also benefitting the surgeon in that the extra oral High volume extraction unit does not require an assistant to maintain position.

To prevent the risk of transmission, especially during the sars-cov-2 pandemic, high risk personal protective equipment has been advised worldwide to varying degrees. In the United Kingdom there has also been an advisory in place for a fallow time after aerosol generating procedures.[55] Both the protective equipment and fallow period are a large departure from the clinical norm and could impact the sustainability and running of dental clinics. Reducing the need to depart from the norm could improve patient access through the reduced wait times post procedure and improve comfort for the operator.

\section{Conclusions}

At the time of completing the present study, there have been no studies comparing the use of external high volume extraction devices in dentistry.

The purpose of the present study was to measure the particle count during dental aerosol procedures and compare the results to when a High Volume Extraction device is used and the results show potentially clinical usefulness to reduce and mitigate some risk of transmission of the SARS-CoV-2 virus.

The aerosols and splatter generated during dental procedures have the potential to spread infection to dental personnel and people within the dental office. While, as with all infection control procedures, it is impossible to completely eliminate the risk posed by dental aerosols, it is important to minimize these risks as far as possible. The results of the present study show that an external high volume extraction device may reduce aerosol particulate count during dental procedures.

Whilst the results of this specific study do not show a direct link between the increased concentration of PM1, PM2.5 or PM10 particulate generated from dental procedures, we have shown that there is a statistically significant increased concentration of PM2.5 and PM10 particulate during each of the five procedures without the use of an external HVE device. We can therefore interpret these results that if the SARS-CoV-2 virus can be held in aerosol droplets and particulate, there is a potentially increased risk of transmission of SARS-CoV-2 from aerosol generating procedures which generate increased concentrations of these sizes of particulate. However, if further study shows that aerosol particulate is produced in an in vivo clinical setting, it may be possible to effectively reduce and mitigate the associated risk with the use of HVE external extraction devices.

A number of limitations are suggested in our in vitro study, namely the in vivo effects such as saliva, blood, breathing, coughing, patient interaction etc which need to be accounted for and may impact the results in an in vivo patient setting. 
It is therefore proposed that a further expanded study is required to asses the impact of increased aerosol generation duration as well as the cumulative effect of other risk mitigating factors such as rubber dam, air purifiers, increased air flow from window opening etc. It is also envisaged that in this expanded study, we can compare these results with expiratory events such as coughing or sneezing directly.

Another limitation was the use of only one type of external high volume extraction device. These devices are new and are not inexpensive. Further study should compare various types and brands to investigate their relative ability to reduce aerosol particulate count in an in vivo clinical setting.

\section{Author Contributions:}

Author: Adam Nulty; Contributed to conception, design, data acquisition and interpretation, drafted and critically revised the manuscript

Author: Patrik Zachrisson; Contributed to conception, design, drafted and critically revised the manuscript

Author: Chris Lefkaditis; Contributed to conception, drafted and critically revised the manuscript

Author: Quintus Van Tonder; Contributed to conception, drafted and critically revised the manuscript

Author: Riaz Yar; Contributed to drafting and critically revised the manuscript

All authors gave their final approval and agree to be accountable for all aspects of the work.

Funding: This research received no external funding.

Acknowledgments: We thank Christopher Orr for the useful discussions and we thank the Chris Celegrat of UKDentistry for his support in providing the the VacStation equipment to enable us to carry out the study at short notice.

Conflicts of Interest: There is no conflict of interest to declare. The author has no financial interests or connections, direct or indirect, that might compromise the perception of the authors as impartial. There is no financial interest that includes commercial or other sources of funding for the author or associated department(s) or organization(s), personal relationships, or direct academic competition.

\section{References}

1. United States Department of Labor Occupational Safety and Health Administration. COVID-19 Control and Prevention /Dentistry Workers and Employers. March 2020 [Internet] Accessed 14th June 2020; Available at: https://www.osha.gov/SLTC/covid-19/dentistry.html]

2. An N, Yue L, Zhao B. Zhonghua Kou Qiang Yi Xue Za Zhi. Cognition of droplets and aerosols in oral clinics and infection prevention and control measures. Chinese Journal of Stomatology. 220; 55(4):223-228.

3. Zemouri C, Volgenant $\mathrm{CMC}$, Buijs $\mathrm{MJ}$, et al. Dental aerosols: microbial composition and spatial distribution. J Oral Microbiol. 2020; 12(1):1762040.

4. Wurie F. Characteristics of exhaled particle production in healthy volunteers: possible implications for infectious disease. F1000 Res 2013; 2: 14.

5. Tang JW, Li Y, Eames I, Chan PKS, Ridgway GL. Factors involved in the aerosol transmission of infection and control of ventilation in healthcare premises.2006; 64(2).

6. Eugen C, Carl E, Cook MS. Characterization of infectious aerosols in health care facilities: An aid to effective engineering controls and preventive strategies. American journal of infection control. 1998; 26(4).

7. Froum S. COVID-19 and the problem with dental aerosols, in Perio-Implant Advisory. 2020; April 7th

8. Acharya S, Priya H, Purohit B, Bhatt M. Aerosol contamination in a rural university dental clinic in South India. Int J Infect Control. 2010; 6:1-7.

9. Hallier C, Williams D, Potts A. 2010 A pilot study of bioaerosol reduction using an air cleaning system during dental procedures. British dental Journal, 2010.

10. Wiley J. 1987. The aerobiological pathway of microorganisms.

11. Kenyon TA, Valway SE, Ihle WW, Onorato IM, Castro KG. Trans- mission of multidrug-resistant Mycobacterium tuberculosis during a long airplane flight. N Engl J Med. 1996; 334(15):933-8. 
12. Yet L. Aerodynamic analysis of SARS-CoV-2 in two Wuhan hospitals. Nature. 2020

13. Chan J, Wet F. A familial cluster of pneumonia associated with the 2019 novel coronavirus indicating person-to-person transmission: a study of a family cluster.Lancet. 2020; 395,514-523

14. Huang C. Clinical features of patients infected with 2019 novel coronavirus in Wuhan, China. Lancet. 2020; 395,497-506

15. CDC. Interim domestic infection control precautions for aerosol- generating procedures on patients with severe acute respiratory syndrome (SARS). Available at: "www.cdc.gov/ncidod/sars/ aerosolinfectioncontrol.htm". Accessed: June 11, 2020.

16. American Dental Association. Severe acute respiratory syndrome (SARS). Available at “www.ada.org/prof/resources/topics/sars.asp". Accessed: June 10, 2020.

17. Leggat PA. Bacterial aerosols in the dental clinic: a review. Int Dent J., 2001; 51(1).

18. Freeman J. Risk of aerosol contamination around the dental chair. Dental nursing. 2013; 9(1).

19. Bentley CD, Burkhart NW, Crawford JJ. Evaluating spatter and aerosol contamination during dental procedures. JADA. 1994; 125: 579-84.

20. Volgenant CMC, de Soet JJ, Cross-transmission in the Dental Office: Does This Make You Ill?. current oral health reports, 2018.

21. Gross KB, Overman PR, Cobb C, Brockmann S. Aerosol generation by two ultrasonic scalers and one sonic scaler: a comparative study. J Dent Hyg 1992; 66:314-8.

22. Miller RL. Characteristics of blood-containing aerosols generated by common powered dental instruments. Am Ind Hyg Assoc J. 1995;56(7):670-676.

23. Sawhney A, Venugopal S, Babu GR, et al. Aerosols how dangerous they are in clinical practice. J Clin Diagn Res. 2015; 9(4):ZC52-ZC57.

24. Bentley CD, Burkhart NW, Crawford JJ. Evaluating splatter and aerosol contamination during dental procedures. J Am Dent Assoc 1994; 125:579-84.

25. Williams GH 3rd, Pollok NL 3rd, Shay DE, Barr CE. Laminar air purge of microorganisms in dental aerosols: Prophylactic procedures with the ultrasonic scaler. J Dent Res. 1970; 49:1498.

26. Miller RL, Micik RE, Abel C, Ryge G. Studies on dental aerobiology: II. Microbial splatter discharged from the oral cavity of dental patients. J Dent Res 1971; 50:621-5

27. Miller RL. Generation of airborne infection by high speed dental equipment. J Am Soc Prev Dent 1976; 6:147.

28. King TB, Muzzin KB, Berry CW, Anders LM. The effectiveness of an aerosol reduction device for ultrasonic scalers. J Periodontol 1997; 68:45-9.

29. Harrel SK. 2004. Airborne spread of disease - the implications for dentistry. Journal of the California Dental Association, 2004; 32(11):901-906

30. Harrel SK, Molinari J. Aerosols and splatter in dentistry: a brief review of the literature and infection control implications. Journal of the American Dental Association. 2004

31. Micik RE, Miller RL, Mazzarella MA, Ryge G. Studies of aerobiology: bacterial aerosols generated during dental procedures. J Dent Res. 1968; 48 : 49- 56.

32. van Doremalen N, Bushmaker T, Morris DH, et al. Aerosol and Surface Stability of SARS-CoV-2 as Compared with SARS-CoV-1. N Engl J Med. 2020; 382(16):1564-1567.

33. Centers for Disease Control and Prevention. Guidelines for infection control in dental health-care settings - Morbidity and Mortality Weekly Report. December 19, 2003/52(RR17);1-61. CDC Guidelines for Infection Control. Atlanta: Centers for Disease Control and Prevention.

34. Abel LC, Miller RL, Micik RE, Ryge G. Studies on dental aerobiology. IV. Bacterial contamination of water delivered by dental units. J Dent Res. 1971; 50(6):1567-1569.

35. WHO scientific brief 27th March 2020 Available at: https://www.who.int/publications-detail/modes-oftransmission-of-virus-causing-covid-19-implications-for-ipc-precaution-recommendations

36. Zhu N, Zhang D, Wang W, Li X, Yang B, Song J, Zhao X, Huang B, Shi W, Lu R, Niu P, Zhan F, Ma X, Wang D, Xu W, Wu G, Gao GF, Tan W. China Novel Coronavirus Investigating and Research Team A novel coronavirus from patients with pneumonia in China. New England Journal of Medicine. 2020; 382:727-733

37. Kan HD, Chen BH, Fu CW, Yu SZ, Mu LN. 2005. Relationship between ambient air pollution and daily mortality of SARS in Beijing. Biomed Environ Sci 18(1):1-4.

38. Kutter JS, Spronken MI, Fraaij PL, Fouchier RA, Herfst S. 2018. Transmission routes of respiratory viruses among humans. Current Opinion in Virology 28:142-151. 
39. Feng C, Li J, Sun W, Zhang Y, Wang Q. 2016. Impact of ambient fine particulate matter (PM2.5) exposure on the risk of influenza-like-illness: a time-series analysis in Beijing, China. Environ Health 15:17.

40. Thomas RJ. Particle size and pathogenicity in the respiratory tract. Virulence. 2013;4:847-858.

41. Morawska L, Cao J. Airborne transmission of SARS-CoV-2: the world should face the reality. Environ. Int. 2020;105730

42. Wang J, Du G. COVID-19 may transmit through aerosol. Ir. J. Med. Sci. 2020:1-2.

43. Duguid JP. The numbers and the sites of origin of the droplets expelled during expiratory activities. Edinb. Med. J. 1945;52:385-401

44. Zhen-Dong G et al. Aerosol and SurfaceDistribution of Severe Acute Respiratory Syndrome Coronavirus 2 inHospital Wards, Wuhan, China. Emerging InfectiousDisease journal. 2020; 26

45. Su W et al. The short-term effects of air pollutants on infuenza-like illness inJinan, China. BMC PublicHealth. 2019; 19,1319.

46. Barnes JB, Harrel SK, Rivera-Hidalgo F. Blood contamination of the aerosols produced by the in vivo use of ultrasonic scalers. J Periodontal 1998; 69:434-8.

47. Infection control recommendations for the dental office and the dental laboratory. ADA Council on Scientific Affairs and ADA Council on Dental Practice. JADA,1996; 127:672-80.

48. Pippen DJ, Verderame RA, Weber KK. Efficacy of face masks in preventing inhalation of airborne contaminants. J Oral Maxillofac Surg. 1987; 45:319-23.

49. Logothetis DD, Martinez-Welles JM. Reducing bacterial aerosol contamination with a chlorhexidine gluconate pre-rinse. JADA. 1995; 126: 1634-9.

50. Harrel SK, Barnes JB, Rivera-Hidalgo F. Reduction of aerosols produced by ultrasonic scalers. J Periodontol. 1996; 67(1):28-32.

51. Klyn SL, Cummings DE, Richardson BW, Davis RD. Reduction of bacteria-containing spray produced during ultrasonic scaling. Gen Dent 2001; 49(6):648-52.

52. Kampf G, Todt D, Pfaender S, Steinmann E. Persistence of coronaviruses on inanimate surfaces and their inactivation with biocidal agents [published correction appears in. J Hosp Infect. 2020; 104(3):246-251.

53. Jacks ME. A laboratory comparison of evacuation devices on aerosol reduction. J Dent Hyg. 2002; $76(3): 202-$ 6.

54. Cochran MA, Miller $\mathrm{CH}$, Sheldrake MA. The efficacy of the rubber dam as a barrier to the spread of microorganisms during dental treatment. JADA. 1989; 199: 141-4.

55. OCDO. Standard operating procedure - Transition to recovery 2020 [Accessed June 10] Available at: https://www.england.nhs.uk/coronavirus/wp-content/uploads/sites/52/2020/06/C0575-dental-transitionto-recovery-SOP-4June.pdf] 